\title{
COMPREHENSIVE DIGITAL DOCUMENTATION AND PRELIMINARY STRUCTURAL ASSESSMENT OF SATUNSAT: A UNIQUE MAYA ARCHITECTURAL LABYRINTH AT OXKINTOK, YUCATAN, MEXICO
}

\author{
D. Rissolo ${ }^{\text {a*, }}$ M. R. Hess ${ }^{\text {a }}$, J. Huchim Herrera ${ }^{\text {b }}$, E. Lo ${ }^{\text {a }}$, V. Petrovic ${ }^{\text {a }}$, F. E. Amador ${ }^{\text {c }}$, and F. Kuester ${ }^{\text {a }}$ \\ ${ }^{a}$ Cultural Heritage Engineering Initiative, University of California, San Diego - (drissolo, mrhess, eklo, vid, fkuester)@ucsd.edu \\ ${ }^{\mathrm{b}}$ Instituto Nacional de Antropología e Historia, Mexico - uaxak810@ gmail.com \\ ${ }^{\mathrm{c}}$ Fundación OLAS, Washington, DC - fabio.esteban@icloud.com
}

Commission II, WG II/8

KEY WORDS: Maya, Yucatan, architecture, laser scanning, photogrammetry, structural analysis

\begin{abstract}
:
Located in the Puuc region of Yucatan, Mexico, the Labyrinth of Oxkintok, also known as Satunsat, is one of the most enigmatic ancient structures in the northern Maya lowlands. Inside this otherwise unremarkable terraced building platform is a series of interconnected vaulted passageways and horizontal ducts that spans three levels. In 2016, we conducted a comprehensive digital documentation of the exterior and interior surfaces and spaces of Satunsat via terrestrial laser scanning (TLS) and structure-frommotion (SfM) photogrammetry. The result is a fused, geometrically accurate, full coverage model with exceptional color and texture fidelity. These data enabled a preliminary structural health assessment and evaluation of the varied masonry techniques employed in the construction of Satunsat and can inform future studies related to the structure's function and meaning.
\end{abstract}

\section{INTRODUCTION}

The ancient Maya site of Oxkintok is situated in the northwestern Puuc region of Yucatan state (Figure 1). This major civic-ceremonial center was occupied from the early facet of the Late Preclassic period (300 BC) until the close of the Terminal Classic period (approximately AD 1000), with the initial construction of monumental architecture occurring closer to AD 300 (Andrews, 1993:6-7). In many ways, Oxkintok can be considered atypical or uncharacteristic of regional Puuc centers, such as Uxmal, Sayil, and Kabah.

The Labyrinth of Oxkintok - Structure 3B1 - is located on the west side of the South Plaza (see Pollock, 1980:290-292). This unique and enigmatic building is also known as Satunsat, which essentially translates to "lost and lost" in Yucatec. Hidden within this otherwise inconspicuous terraced building platform (Figure 2) is a complex series of interconnected vaulted passageways, stairwells, and horizontal ducts that spans three levels - a relatively remarkable feat of engineering.

In addition to possibly functioning as an observatory (Šprajc, 1990; 1995), Satunsat has also been interpreted as a symbolic cave and may have served as an architectonic metaphor for the underworld (or Xibalba, the Maya "place of fright"). In fact, Satunsat was referred to as a cave by the nearby residents of Maxcanu during the $19^{\text {th }}$ century. The phenomenon of architectural caves is well documented and lies along a continuum of subterranean or semi-subterranean spaces, including artificial caves (see Brady, 1992).

Comprehensive digital documentation allows us to visualize the superimposition of levels and better evaluate the relationships between the different physical elements of the Labyrinth that would otherwise be imperceptible. It is from such a model that future studies can proceed.

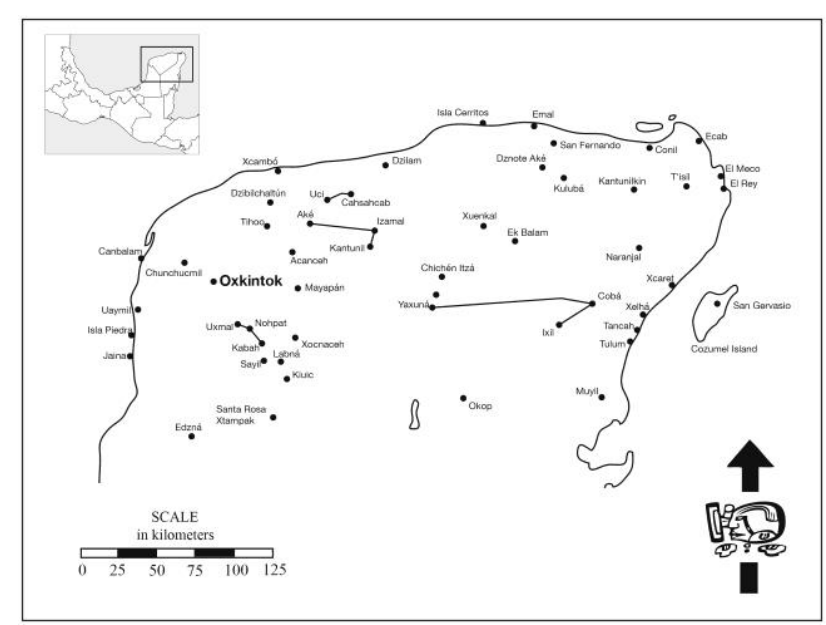

Figure 1. Archaeological site map of the northern Yucatan Peninsula, with Oxkintok indicated (J.B. Glover)

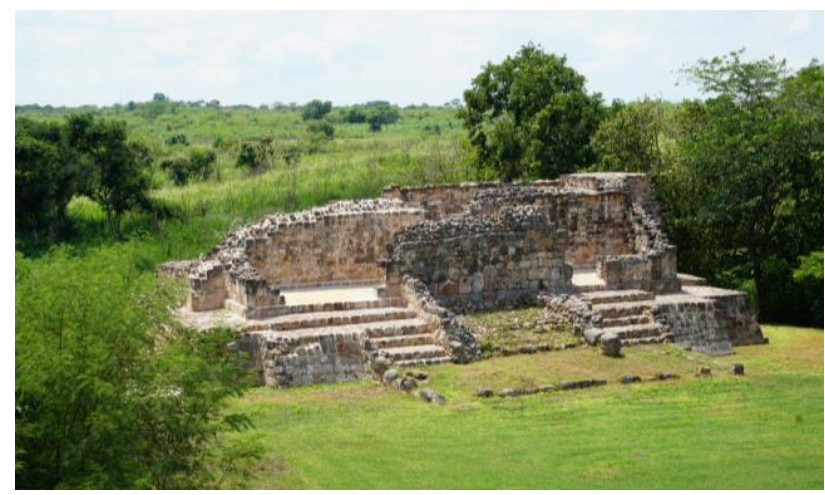

Figure 2. Satunsat (Structure 3B1), South Plaza (D. Rissolo)

\footnotetext{
* Corresponding author
} 


\section{PAST STUDIES}

The first plan of the Labyrinth was produced by Henry C. Mercer (1896) with a subsequent survey not appearing until H.E.D. Pollock published his volume on Puuc architecture (1980). The civic-ceremonial center of Oxkintok was the focus of a multiyear archaeological research campaign conducted by the Misión Arqueológica Española en México from 1986-1991 and included resurvey and excavation of Satunsat (Ferrándiz Martín, 1990; Rivera Dorado, 1987; Rivera Dorado, Amador Naranjo, 1994; Rivera Dorado, Ferrándiz Martín, 1989).

Plans and sections were created by Alfonso Muñoz Cosme (see Rivera Dorado, Ferrándiz Martín, 1989:figs. 9-12) and separately (and somewhat concurrently) by George F. Andrews (1993). These earlier surveys reflect varying degrees of accuracy and detail and did not fully capture the true geometry of the Labyrinth.

\section{RECENT FIELD AND LAB EFFORTS}

\subsection{Data Capture Methodology}

A numerical model of the Satunsat structure was achieved via a comprehensive program of terrestrial laser scanning (TLS) and SfM photogrammetry. Coverage of the exterior and interior surfaces of the structure involved 103 scans using a Faro Focus3D X 130. Although the scanner's camera was employed during the sunlit exterior acquisition, it was not used in the dark interior of the structure.

To acquire data for the exterior upper-level spine walls and the roof of Satunsat, 421 aerial images were taken with a DJI Inspire 1 Pro with a DJI Zenmuse X5 Pro camera (using a $15 \mathrm{~mm}$ lens). These image-derived point data were later merged with the TLS point data.

The authors decided to perform a comprehensive and systematic photogrammetric image acquisition of all interior surfaces to both complement the geometric reconstruction achieved via the TLS survey (realized through fusion of both data sets) and to provide the highest possible RGB fidelity, which in turn enabled researchers to better evaluate the mortar and varied masonry techniques employed in the construction of Satunsat and to better assess the structure's current state of conservation.

Image acquisition for SfM photogrammetry proved challenging. With the goal of comprehensive, high-resolution coverage, each passageway was imaged via 6-8 passes, which involved oblique runs of each wall, vaulted ceiling, and floor (from two directions). All adjoining doorways and stairwells were imaged, including all jams and lintels and all stair risers, treads, and landings (from multiple directions). Agisoft targets were placed in key locations throughout the tunnels and stairwells. In all, 3,208 images were acquired resulting in 3.3 billion points for the interior photogrammetry model.

The camera used throughout the interior acquisition was a Sony a7rII with a $16-35 \mathrm{~mm} \mathrm{f} / 4$ lens (set at $16 \mathrm{~mm}$ and in aperture priority mode) and mounted in vertical (or portrait) position. The latter configuration was selected to better frame the vault spring, wall, and wall-floor junctions in each exposure (when imaging the vaulted passageways). Key to optimal results was the use of on-board differently dimmable LED light panels that effectively mitigated both shadow and occlusion issues.

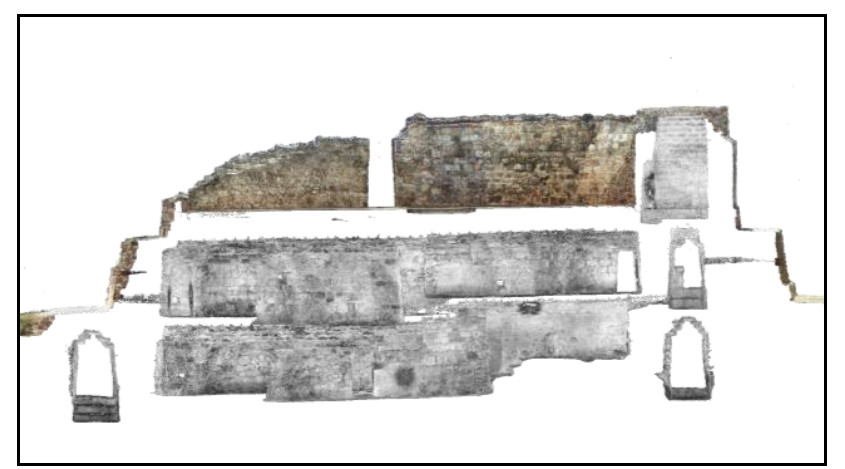

Figure 3. Longitudinal section view of Satunsat, facing west

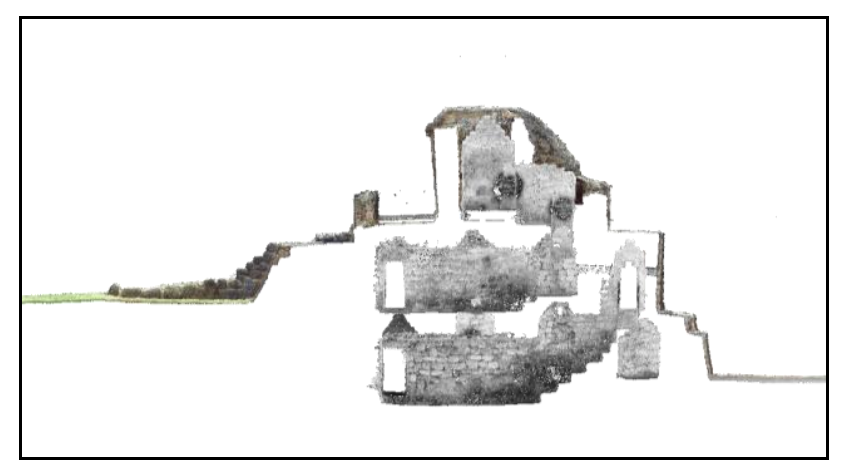

Figure 4. Transverse section view of Satunsat, facing south

\subsection{Data Processing and Post-Processing}

Following the field acquisition, FARO SCENE was used for TLS data processing and registration. Images for SfM photogrammetry were preprocessed for image quality, and then processed through Agisoft PhotoScan 1.4.2 to create the 3D digital surrogate. Preprocessing consisted of a number of steps to ensure the quality of the images to be used in the reconstruction. For example, exposure correction and tone mapping can be applied to the imagery in the form of decreasing contrast, reducing highlights, and brightening shadowed or darker areas. If necessary, noise reduction can also be applied before exporting the images for use in the $3 \mathrm{D}$ reconstruction.

The TLS point cloud and the image-derived dense point cloud were then imported into Viscore - a custom point-based interactive visual analytics engine - for fusion and analysis. The fusion of data produced by different imaging modalities (including those used in this study, but also potentially GPR, thermography, or hyperspectral imaging) allows for the visualization and analysis of different phenomena related to the target site (see Lahat et al., 2015).

Viscore enables virtual exploration of the site via the collected data and derived products, seamlessly visualizing both 3D and 2D data, as well as both point clouds and meshes. By allowing multiple complementary representations of the site to be consulted interactively, Viscore offers a flexible, hands-on approach for fusing data from different modalities.

In addition to point clouds and meshes, we can instantaneously access the entire corpus of photogrammetrically-processed images while navigating through the virtual representation of 
the site. Each of the original high-resolution photographs can be projected or draped on demand onto the corresponding section of the point cloud, allowing convenient access to all captured views of any given site feature. The ability to interactively inspect select geospatially referenced photographs enables the domain expert to more accurately identify and characterize those features not visible in the point cloud or the textured mesh. For the interior of Satunsat, this proved particularly useful in discerning between different mortar and chinking materials and techniques as well as examining the relationships between masonry and bedrock.

While we can perform "virtual fieldwork" with access to the full site record using Viscore, it is also useful to generate derived products such as $2 \mathrm{D}$ maps and $3 \mathrm{D}$ meshes. To produce a simplified textured 3D mesh suitable for web and mobile viewing, we first attempted to use PhotoScan exclusively - but encountered problems with running the dense reconstruction and meshing for the complete interior image set, requiring us to process the imagery in multiple chunks, with multiple resulting dense clouds which we subsequently aligned in Viscore.

Starting with the aligned dense point clouds in Viscore, we first manually remove extraneous points (e.g. reconstruction errors, instruments, personnel; using a brush point selection tool), then subsample and filter the point cloud in Viscore to drop isolated points (i.e. those with few neighbors within a chosen threshold distance), then export the resulting point cloud and use the Poisson mesh reconstruction tool (Kazhdan et al., 2006) to generate a mesh, which we finally import into PhotoScan to texture with the aligned images, and ultimately export as a mesh with texture coordinates and corresponding texture image.

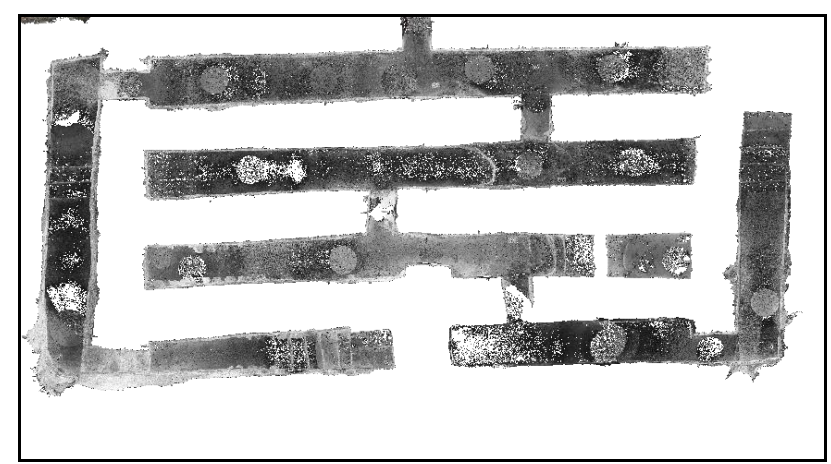

Figure 5. Plan view of Satunsat level 1

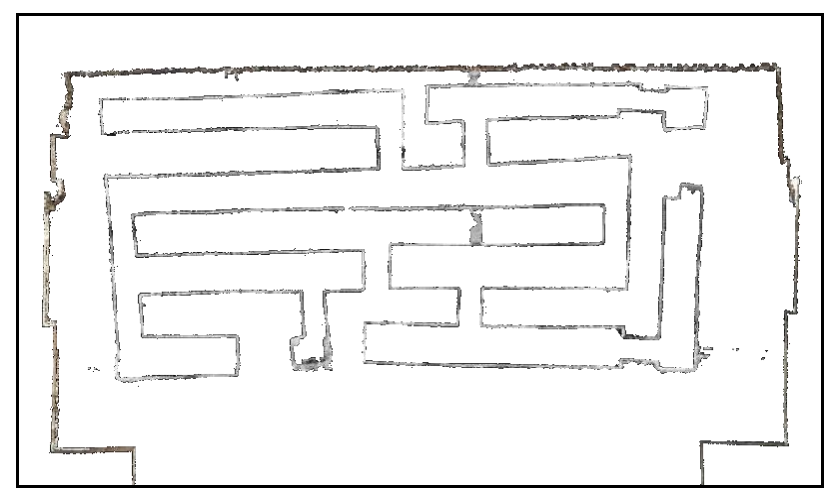

Figure 6. Plan view of Satunsat level 2

\subsection{Preliminary Structural Assessment}

Recent 3D documentation enables researchers to better examine the complex morphology of Satunsat while making possible a more accurate structural health assessment, which was initiated as part of this study.

Of particular interest is the remarkable ability of the irregular, corbelled vaults and relatively narrow spine walls to distribute and bear the overlying mass of the structure. The earlier slab style of Satunsat's masonry vaults differs significantly from the veneer and concreted core technique characteristic of later Puuc vaulted architecture. Also noteworthy is the relationship between the plaza, the structure's masonry components, and its bedrock foundation.

Essentially, the numerical model can facilitate a more detailed study of the structural implications of the varied construction techniques. As shown in the sections and plans (Figures 3-6), the intricate alignment of vaulted spaces, lintels, and spine walls ensured a certain degree of structural integrity. Autodesk Inventor was employed to perform finite element analysis (FEA) of Satunsat to determine the overall structural response. It is important to note that a hypothetical homogenous material was used in place of the heterogenous masonry. It should also be noted that the western façade of Satunsat was consolidated and partially reconstructed in late 1980s (see Rivera Dorado, Ferrándiz Martín, 1989).

Initial numerical simulations (gravity load stress) resulted in a range of damage scenarios, which in turn can inform future preventative reinforcement strategies or location-specific interventions (Figure 7). Analysis of as-built masonry construction is inherently difficult and requires certain assumptions; however, the dense measurements enable a more accurate characterization the structure's response to external forces.

TLS and SfM documentation also revealed more naturalized tunnel forms as well as the relationship between carved bedrock and masonry. Results suggest that the cave-like nature of the passageways in Satunsat is not incidental, but rather reflects the interplay between domains more common to Maya notions of sacred space.

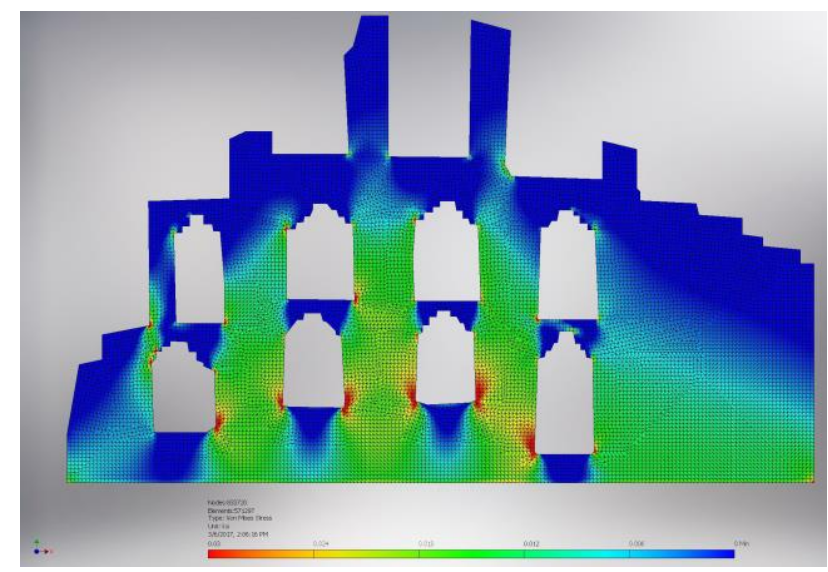

Figure 7. Preliminary gravity load stress modeling 


\section{CONCLUSIONS}

The level of accuracy and fidelity achieved was unprecedented for Satunsat - one of the most unique buildings ever constructed by the ancient Maya. It is from these data that a broad range of studies can proceed, including next-phase structural analysis and structural health assessment. Moreover, the numerical model can enable, for the first time, archaeoastronomical experimentation via appropriate software. Indeed, these fused data offer experts in ancient Maya architecture, working in conjunction with structural engineers, the opportunity to better describe, model, and ultimately understand the techniques used to realize a massive, multistoried construction such as Satunsat.

\section{ACKNOWLEDGEMENTS}

Research was conducted under the auspices of the Instituto Nacional de Antropología e Historia (INAH) and made possible by Binar Media, National Geographic Latin America, Sony Electronics, and the Strauss Family Fund for Mesoamerican Studies. We would like to thank the following individuals for their invaluable contribution to the project: Zoë Abrahams, Jeffrey Glover, Jennifer Hollis, Kenta Honjo, Oliver Huang, Crystal Liu, Christopher McFarland, Dominique Meyer, Alejandro Ravazzola, Dario Schvarzstein, Brittany Whiting, and Luciana Xavier Gibson.

\section{REFERENCES}

Andrews, G. F., 1993. Architectural Survey at Oxkintok: 19711993. The George F. and Geraldine D. Andrews Papers, the Alexander Architectural Archive, University of Texas Libraries, University of Texas, Austin, pp. 1-147.

Brady, J. E., 1992. Man-Made and Pseudo-Karst Caves: The Implications for Subsurface Features within Maya Centers. Geoarchaeology, Vol. 7(2), pp. 149-167.

Ferrándiz Martín, F., 1990. El Interior del Laberinto, In: Oxkintok 3, Misión Arqueológica Española en México, Madrid, pp. 73-85.

Kazhdan, M., Bolitho, M., Hoppe, H., 2006. Poisson Surface Reconstruction. In: Eurographics Symposium on Geometry Processing, pp. 61-70.

Mercer, H. C., 1896. The Hill Caves of Yucatan. Lippencott, Philadelphia.

Lahat, D., Adall, T., and Jutten, C., 2015. Multimodal Data Fusion: An Overview of Methods, Challenges, and Prospects. In: Proceedings of the IEEE, Vol. 103(9), pp. 1449-1477.

Pollock, H.E.D., 1980. The Puuc: An Architectural Survey of the Hill Country of Yucatan and Northern Campeche, Mexico. Memoirs of the Peabody Museum of Archaeology and Ethnology, Vol. 19. Harvard University, Cambridge.

Rivera Dorado, M., 1987. El Satunsat o Laberinto. In: Oxkintok 1, Misión Arqueológica Española en México, Madrid, pp. 1929.

Rivera Dorado, M., Amador Naranjo, A., 1994. El laberinto de Oxkintok. In: VII Simposio de Investigaciones Arqueológicas en Guatemala, 1993, Museo Nacional de Arqueología y Etnología, Guatemala, pp. 600-606.

Rivera Dorado, M., Ferrándiz Martín, F., 1989. Excavaciones en el Satunsat. In: Oxkintok 2, Misión Arqueológica Española en México, Madrid, pp. 63-75.

Šprajc, I., 1990. El Satunsat de Oxkintok: ¿Observatorio Astronómico? In: Oxkintok 3, Misión Arqueológica Española en México, Madrid, pp. 87-97.

Šprajc, I., 1995. El Satunsat de Oxkintok y la Estructura 1-Sub de Dzibilchultun: Unos Apuntes Arqueoastronómicos. In: Memorias del Segundo Congreso Internacional de Mayistas, Universidad Nacional Autónoma de México, Mexico, pp. 585600 . 